\title{
AC 2010-2003: ENGINEERING DECISIONS IN THE CONTEXT OF SUSTAINABILITY: COMPLEX SYSTEMS
}

\section{George Catalano, State University of New York, Binghamton}

\author{
Caroline Baillie, Western Australia
}




\title{
Engineering Decisions in the Context of Sustainability: Complex Systems
}

\begin{abstract}
In the present work, we suggest that too often our views of the ethical dimension of the engineering profession may at times be unduly limited. We offer that viewing questions surrounding ethical dilemmas in the context of complex systems theory and associated ethical elements may be a way to broaden our sense of responsibility towards all of those with whom we share the Earth. We focus on one aspect of the nexus of environmental and societal concerns: issues related to sustainability. Using complex systems theory and associated ethical implications, we consider the case of the effects of tourism on the native culture of Hawaii.
\end{abstract}

\section{Introduction}

Ethical issues, which confront the engineering community, can be separated into two main categories: micro-ethics that focuses mainly upon issues that arise on a daily basis and macro-ethics that more broadly is concerned with the allocation, the use and the management of societal and environmental resources. In our view, ethical education at the undergraduate level has been centered at the micro-ethics level with less attention paid to the broader ethical issues that arise when considering the impacts of engineering upon society and the environment. Our approach in the present work shall be to specifically limit our consideration of such issues to an important nexus of societal and environmental ethical dilemmas, those related to sustainability.

Engineering is a profession with an important ethical dimension. ${ }^{1}$ It is our perspective that we in engineering need to reconsider our sense of ethical responsibility towards not only the health of the natural environment but to include also the health and vibrancy of local societies in which we work in a much broader way. Far too often it seems that we have not done a very good job with respect to either. Yet we do not think it is because we are members of an unethical profession. Perhaps it is because our ethical frameworks for making decisions are too limited or confined.

Ethical issues related to sustainability seem ideally suited to complex systems analysis. Therefore an important converging goal of the present effort focuses upon examining the issues that arise in considering sustainability with not only the more traditional foundational frameworks for ethical decision-making but also those based on paradigms more in alignment with our present day understanding of complexity.

With respect to sustainability, we must be prepared to ask and answer the following questions: What is the meaning of sustainability? Who must be included in the determination of what is to be sustained? Should we be concerned not with the meaning 
of sustainability but rather the implications of sustainability as they affect the status quo? Ultimately, why is sustainability even desirable? With respect to complexity, we shall explore the implications of non-linearity and emergence, the preference for differentiation and the notion of interconnectedness that characterize complex systems. How do these fundamental principles of complex systems influence our ethical decisionmaking? How do they change - if at all- our understanding of our ethical responsibilities towards society and towards the environment?

\section{Sustainability}

Sustainability refers to the capacity to endure. In ecology, sustainability describes how biological systems remain diverse and productive over time. For humankind, it is the potential for long-term maintenance of wellbeing, which in turn depends on the health of the natural world and the prudent use of natural resources. The Brundtland Commission ${ }^{2}$ considers sustainable development and offered the following definition of this term:

"Sustainable development is development that meets the needs of the present without compromising the ability of future generations to meet their own needs. It contains within it two key concepts:

- the concept of 'needs', in particular the essential needs of the world's poor, to which overriding priority should be given; and

- the idea of limitations imposed by the state of technology and social organization on the environment's ability to meet present and future needs."

Gillman $^{3}$ extends this goal oriented definition by stating "sustainability refers to a very old and simple concept (The Golden Rule)...do onto future generations as you would have them do onto you."

In an effort to clarify specific human and environmental parameters for modeling and measuring sustainable developments, the following definitions are more specific:

- "Sustainable means using methods, systems and materials that won't deplete resources or harm natural cycles." 4

- Sustainability "identifies a concept and attitude in development that looks at a site's natural land, water, and energy resources as integral aspects of the development." 5

- "Sustainability integrates natural systems with human patterns and celebrates continuity, uniqueness and placemaking." 6

In review of the totality of these definitions, it seems that the site or the environmental context is an important variable to most working definitions of sustainability.

Let us consider the approaches that a variety of engineering organizations and societies have adopted in dealing with the ethics of sustainability. Recent changes in professional society policies and codes of ethics reflect changing attitudes in engineering. Several professional societies, the National Society of Professional Engineers (NSPE), and the 
American Society of Civil Engineers (ASCE) have added sustainability to their ethical guidelines. A revision to the NSPE Code of Ethics ${ }^{7}$ (2006) incorporated an ethical obligation for sustainability. Subsequently the statement was further clarified to read:

- NSPE Code of Ethics

"Engineers shall at all times strive to serve the public interest. Engineers are encouraged to adhere to the principles of sustainable development in order to protect the environment for future generations."

This is further clarified in Footnote 1:

- Footnote 1 "Sustainable development" is the challenge of meeting human needs for natural resources, industrial products, energy, food, transportation, shelter, and effective waste management while conserving and protecting environmental quality and the natural resource base essential for future development. ${ }^{8}$

The American Society of Civil Engineers (ASCE) was the first professional engineering society to incorporate sustainability requirements into their code of ethics. ${ }^{9}$ In November 1996, the ASCE Board of Directors added sustainability principles to Canon 1 and Canon 3:

- Canon 1.

"Engineers shall hold paramount the safety, health and welfare of the public and shall strive to comply with the principles of sustainable development in the performance of their professional duties;"

and

- Canon 3.

"Engineers shall issue public statements only in an objective and truthful manner.

$\circ$ Engineers should endeavor to extend the public knowledge of engineering and sustainable development, and shall not participate in the dissemination of untrue, unfair or exaggerated statements regarding engineering."

In addition to the changes in the Code of Ethics, ASCE has supported a number of other policies and initiatives in furtherance of sustainability. Policy $418^{10}$ ("The Role of the Civil Engineer in Sustainable Development)," which encourages civil engineers to consider economic development and environmental sustainability as "complementary aspects of the common goal of improving the quality of life." Policy 418 went on to offer the following implementation strategies:

"Promote broad understanding of political, economic, social and technical issues and processes as related to sustainable development. Advance the skills, knowledge and information to facilitate a sustainable future; including habitats, natural systems, system flows, and the effects of all phases of the life cycle of projects on the ecosystem. Advocate economic approaches that recognize natural resources and our environment as capital assets. Promote multidisciplinary, whole 
system, integrated and multi-objective goals in all phases of project planning, design, construction, operations, and decommissioning. Promote reduction of vulnerability to natural, accidental, and willful hazards to be part of sustainable development. Promote performance based standards and guidelines as bases for voluntary actions and for regulations, in sustainable development for new and existing infrastructure."

In a subsequent report, The Vision for Civil Engineering in $2025,{ }^{11}$ civil engineers are seen as "master builders, environmental stewards, innovators and integrators; managers of risk and uncertainty; and leaders in shaping public policy." Lastly, the ASCE Board of Directors approved the release of the Sustainable Development Action Plan ${ }^{12}$ (2008), which summarized the society's achievements and outlined new objectives in education, outreach activities, and research in relation to sustainable development. Further it challenged "civil engineers to fully understand, embrace, and apply the principles and practices of sustainability in their work."

The American Society of Heating, Refrigerating and Air-Conditioning Engineers (ASHRAE) has also included sustainability in their policies and guidelines as described in Standards 90.1 and 90.2 for energy efficiency. ${ }^{12}$ ASHRAE's "Sustainability Roadmap" sets forward the following set of overarching goals:

- "Expand our efforts to foster sustainable buildings.

- Conduct our own affairs in a sustainable manner.

- Lead in researching technologies that enable the design and application of sustainable HVAC\&R equipment and systems.

- Partner with appropriate sustainability advocacy organizations where our strengths are complementary.

- Develop materials and programs related to sustainability to educate and inspire the current and next generation of members."

The American Society of Mechanical Engineers (ASME) has included sustainability in its Code of Ethics ${ }^{13}$ in Fundamental Canon 8:

- "Engineers shall consider environmental impact and sustainable development in the performance of their professional duties."

In addition, many state government departments of transportation, the U.S. government's Environmental Protection Agency (EPA) and the Association of State and Territorial Solid Waste Management Officials (ASTSWMO) all support sustainability in guides, reports, and legislation. ${ }^{14}$ While it is clear that more and more professional societies are including ethical responsibilities related to sustainability, what remains unclear is how to address issues of sustainability from an ethical perspective.

We have adopted the contextual sustainability education (CSE) model ${ }^{15}$ as our approach to bring forward the ethical issues related to sustainability and engineering. CSE as a framework for education is based upon the premise that the integrity of the natural world is not a separate issue from others associated with social justice and peace. As Orr notes, "the reformers of education often fail to identify and resolve the problem of education 
itself because they do not recognize how education is often subject to a community of often implicit assumptions. Therefore it is important for us to describe the explicit assumptions that we are making in using the CSE framework:

- Assumption 1. The Earth (as well as the rest of the Cosmos) is unfolding rather than static. With developments in science, we have begun "to experience time as an evolutionary sequence of irreversible transformations."

- Assumption 2. Human life is derivative rather than primary; that is, humans are members of a "web of life, and together with other life forms constitute the Earth community."

- Assumption 3. We adopt a bioregional environmentalism principle, which requires that "the Earth's well-being depend upon the maintenance and restoration of the Earth's life support processes and service. Bioregional environmentalism adds that the notion that humans are to be living within the opportunities and limits of their local biophysical region, that is, the region that is typically determined by its watershed.

\section{Complexity and Ethics}

As science has begun to ask where the enduring features of Nature come from and how they work, the answer seems to be "complex systems." With scientific advances, and as the modern problems related to sustainability arise at an accelerating rate, a new kind of science is emerging that requires being openly exploratory, using all the analytical skills as well as creativity, and incorporates an awareness and respect for the perspectives of others, in order to develop complex knowledge systems matching the variety of the complex system problems that arise.

Early contributors to the pure physics theory of complex systems included Prigogine, Feigenbaum and Mandelbrot. Prigogine ${ }^{16}$ developed dissipative structure theory, which led to fundamental research in self-organizing systems, as well as philosophic inquiries into the formation of complexity on biological entities and the quest for a creative and irreversible role of time in the natural sciences. Feigenbaum ${ }^{17}$ pioneered studies in chaos theory led to the discovery of what are referred to as the "Feigenbaum constants" which enabled mathematicians to take their first steps to unraveling the apparently intractable "random" behavior of chaotic systems. Mandelbrot ${ }^{18}$ was largely responsible for the present interest in fractal geometry. He showed how fractals can occur in many different places in both mathematics and elsewhere in the natural world.

In complex systems, the emphasis of study is in regions far from equilibrium and their behavior may be characterized as highly non-linear. Implicit in complex systems is recognition of sensitivity to initial conditions and path dependency. Perhaps put another way, there are no repeating events in a complex system. The totality of these attributes seem ideally matched to our effort to understand issues that arise from sustainability. Complex systems theories concern systems that function in 'far from equilibrium' conditions unlike the earlier theories that focus on understanding the conditions for the maintenance of stable or equilibrium conditions, Complex systems theories focus upon 
the clarification of system dynamics. Such dynamics include the processes and paths followed to move from one state to another as well as their beginning and ending points. These newer theories have not replaced, but instead have supplemented the earlier general systems model most notably the linear and mechanical models that can now be regarded as describing a special type of system embedded in a much wider array of phenomena.

Characteristics and processes, which exemplify complex systems, include:

- Holism rather than reductionism - that is, a complex system is not simply a collection of its parts

- Entropy - that is, complex systems proceed in a manner in which disorder is favored over order

- Emergence - that is, complex systems may behave in ways which are totally unexpected and unpredictable

- Interdependence - that is, the different elements of a system have a relationship with other elements in the system

\section{Ethical Implications}

An ethical framework for dealing with dilemmas that arise in complex systems theories has been offered by Berry ${ }^{19}$ and Swimme and Berry ${ }^{20}$ who point out the fundamental principles of all complex systems as follows:

- Subjectivity - by subjectivity the contrast is sharply made to objectivity or objectification. Each element of a complex system can be seen as having an inner presence or reality and each has an interest in the functioning of the system as a whole.

- Differentiation - by differentiation is meant that -left by themselves- complex systems tend to evolve new and different elements. Evidence can be found in the evolutionary path followed by life on Earth as more and more plant and animal species naturally and continually evolve.

- Community - by community is meant that each part of a complex system is intimately connected with every other part. Each part has an important role to play in the evolution of the complex systems.

An ethically responsible decision for a complex system then would: recognize the potentialities within each of the separate elements of the system, respect and nurture diversity, and recognize the value that each part brings to the complex system as a whole. An ethically irresponsible decision for a complex system then would: deny the potentialities within each of the separate elements of the system, move towards homogeneity, and focus on the individual parts or elements of a complex system irrespective of their connections to the whole. In the next part of the present work, we shall explore the kinds of questions that may arise when we attempt to implement our complex systems approach to an ethical dilemma.

\section{A Case for Consideration}


According to many native voices, tourism development in Hawaii most often takes place at the expense of the indigenous people's cultural and historical symbols and land based resources. ${ }^{21}$ They further suggest that tourism development has played a major role in the destruction of ancient Hawaiian burial grounds, significant archaeological historic sites and sacred places with almost every major resort development having been built on some culturally significant site. Another major impact of tourism on Native Hawaiians can be understood in the context of environmental exploitation. ${ }^{22}$ The character of indigenous Pacific cultures in relationship to the land is one based on a high level of environmental awareness and ecological conservatism. ${ }^{22}$ The relationship of people to land, and people to sea, is spiritual and religious. Land is the base around which a culture evolves. When tourism takes away the land, takes away access to the fishing grounds or the right to gather food or medicine, the Hawaiian loses a primary means of livelihood, and more importantly, meaning in life.

Let us then examine the following scenario. Suppose you as an engineer are hired to design a new hotel resort on the previously relatively undeveloped northern shore of Oahu island. The new resort has been mandated to be state of the art in green design and green engineering. Solar and wind energy sources are used extensively to reduce the environmental impact of the new hotel complex. New construction will bring a significant influx of new jobs and new workers. The resort management has set the goal of hiring natives to work at the service jobs associated with maintaining the complex. The question then is straightforward: should you as an engineer participate in the project? Specifically, is it ethical to participate? What kinds of considerations may go into that determination?

With only a careful consideration of the various existing codes of ethics described earlier in the present work, it would be difficult to come to any conclusion other than that the decision to go ahead with the hotel resort project is an ethical one from an engineering perspective. Attention is paid to environmental concerns. From a green engineering point of view, the project seems quite exciting and positive. From a societal perspective, the plan seems to bring the prospect of an influx of new jobs to an area which has been heretofore removed from development.

What decision might we reach if we consider the project in terms of the ethical consequences of the complex systems model? The criteria include subjectivity, differentiation and community. If we consider subjectivity, we may consider the ecosystems that exist now and reflect upon the notion that such ecosystems are the end products of the creativity of the Earth itself. Additionally we may wish to consider the residents of the area and their culture as has evolved through countless generations. When we consider differentiation, will the planned new development introduce new plant and animal species that will in effect crowd out the native species? Will the numbers of species increase, decrease or remain relatively unaffected? Lastly the issue of community suggests a careful consideration of the interests of many voices that are too often ignored. How does the new development fit into the world-views of the native cultures? Perhaps, 
even more importantly, do we even know what those views are and how they might be different than ours?

\section{Concluding Thoughts}

With great respect and appreciation for the countless contributions that engineering has made to the quality of life for many on the planet, we are simply suggesting that our views on the ethical dimension of the profession may at times be too limited. We offer that viewing questions surrounding ethical dilemmas- in the present work we focused on sustainability- in the context of complex systems theory and associated ethical elements may be a way to broaden our sense of responsibility towards all of those with whom we share the Earth.

\section{Personal Comment}

A recent ASEE Annual Conference was held near Waikiki Beach in Honolulu. Any mention of Waikiki Beach, immediately conjures up images of beautiful white beaches, breathtaking panoramas, waves that meet the needs of even the most adventuresome surfer, throngs of tourists parading along the sea-side promenade, thousands more busily going from exclusive boutique to novelty store, arms loaded down with countless boxes and shopping bags. Looking eastwards, there lies the magnificent Diamond Head peak perhaps most inspiring when shrouded in morning mists. Everywhere one looks there are the beautiful people of wealth and high fashion. Certainly, Waikiki Beach is nothing less than paradise here on Earth or is it? What about the people who inhabited the island long before Captain Cook landed?

Late one evening during the conference, we came across a homeless man who spoke of life in Honolulu and Waikiki Beach prior to huge influx of foreign and American tourists. Things were certainly much different than they were in the 1950's when he first arrived. He spoke eloquently of how the native culture was no longer strong nor as vibrant as it once was. Now he felt an outsider in the land he once called home. The juxtaposition of that homeless man with his garbage bag filled with his entire earthly holdings alongside the opulence of lavish meals served at ocean-side restaurants is an image that has haunted us. The present work is our effort to respond.

\section{References}

1. Davis, Michael, Thinking Like an Engineer, Oxford University Press, 1998

2. Bruntland Commission (1987) Our Common Future, World Commission on Environment and Development, 1987. Published as Annex to General Assembly document A/42/427, Development and International Cooperation: Environment, August 2, 1987. Retrieved, 2007.11.14

3. Gilman, R., Sustainability from the 1992 UIA/AIA "Call for Sustainable Community Solutions", 1992.

4. Rosenbaum, R.from Mahaffy, M., http://www.arch.wsu.edu/09\%20publications/sustain/defnsust.htm, 1993

5. Veira from Mahaffy, M., http://www.arch.wsu.edu/09\%20publications/sustain/defnsust.htm, 1993.

6. Early from Mahaffy, M., http://www.arch.wsu.edu/09\%20publications/sustain/defnsust.htm, 1993.

7. NSPE Code of Ethics, http://www.nspe.org/Ethics/CodeofEthics/index.html 
8. NSPE Code of Ethics, http://www.nspe.org/Ethics/CodeofEthics/index.html

9. ASCE Code of Ethics, http://temp.onlineethics.org/codes/ASCEcurrent.html

10. ASCE Policy 418, The Role of Civil Engineer in Sustainable Development, http://content.coprinstitute.org/files/pdf/ASCEPolicyStatementSustainableDevelopment.pdf, 2007.

11. ASCE, The Vision for Civil Engineering in 2025, http://content.asce.org/files/pdf/TheVisionforCivilEngineeringin2025_ASCE.pdf

12. ASHRAE Sustainability Roadmap, http://www.ashrae.org/content/ASHRAE/ASHRAE/ArticleAltFormat/200621485921 886.pdf

13. ASME Code of Ethics, http://files.asme.org/ASMEORG/Governance/3675.pdf

14. www.epa.gov

15. Verhagen, F.C., Contextual Sustainable Education, Educating for a Culture of Social and Ecological Peace, ed. A.Wenden, SUNY Press

16. Prigogine, Ilya; Stengers, Isabelle, Order out of Chaos: Man's new dialogue with nature. Flamingo Press, 1994.

17. Feigenbaum, M. J., "Quantitative Universality for a Class of Non-Linear Transformations". J. Stat. Phys. 19: 25-52, 1978.

18. Mandelbrot, B., The Fractal Geometry of Nature, W.H. Freeman, 1982.

19. Berry, T., The Sacred Universe: Earth, Spirituality, and Religion in the 21st Century, Columbia University Press, 2009.

20. Berry, T., and Swimme, B., The Universe Story, Harper San Francisco, 1994.

21. Benham, M.K.P.A., and Heck, R., Culture and Educational Policy in Hawaii: The Silencing of Native Voices, Routledge, 1998.

22. Eleihiwa, L., Native Land and Foreign Desires: How Shall We Live in Harmony, Bishop Museum Press, 1992. 